\section{Diagnosis of neurofibromatosis type 1 after resection of intercostal nerve neurofibroma}

\author{
Borja Aguinagalde, ${ }^{1}$ Jon Zabaleta, ${ }^{1}$ \\ Marta Fuentes, ${ }^{1}$ Nerea Bazterargui, ${ }^{1}$ \\ Carmen Lobo, ${ }^{2}$ José Miguel Izquierdo' \\ 'Department of Thoracic Surgery; \\ 2Department of Pathology, Donostia \\ Hospital, Donostia-San Sebastian, Spain
}

\section{Abstract}

We report a case of a 37-year-old man with an asymptomatic extraparenchymal mass in the left hemithorax. Complete surgical removal of the tumour was achieved through a minithoracotomy and histological analysis confirmed the diagnosis of myxoid neurofibroma. Given this histological diagnosis, the patient was re-examined and many café au lait spots (more than 6, larger than $15 \mathrm{~mm}$ in diameter) and neurofibromas (elastic tissue) were observed and the patient was diagnosed with neurofibromatosis (NF) type 1 (von Recklinghausen's disease). We have found only eight case reports of neurogenic tumours originating from an intercostal nerve; only two of these corresponded to neurofibromas. Among these two patients, only one was a case of NF type 1 and, in contrast to our case, the diagnosis was reached prior to surgery. We present a very rare case of intercostal nerve neurofibroma leading to a definitive diagnosis of NF type 1.

\section{Introduction}

Neurogenic tumours are common in the thoracic cavity, most originating from the mediastinum and only rarely from the intercostal nerves. More than $95 \%$ of these tumours correspond to neurilemmomas (also known as schwannomas) or neurofibromas. Up to $45 \%$ of patients with intercostal neurofibromas have NF type 1 (von Recklinghausen's disease). ${ }^{1} \mathrm{We}$ present a case in which a diagnosis of NF type 1 was made after the resection of an incidentally discovered neurofibroma of the sixth intercostal nerve.

\section{Case Report}

A 37-year-old man was found to have an asymptomatic extraparenchymal mass in the left hemithorax, during examination prior to vocal cord nodule surgery. The patient reported that ten years earlier he had been told he had a benign pleural mass (no images or reports), but had no other relevant medical history. On physical examination, it was not possible to palpate the lesion, but a chest X-ray showed an extrapleural mass with well-defined margins at the level of the eighth rib. A subsequent thoracic computed tomography scan confirmed the presence of an extraparenchymal lesion in the eighth intercostal space, with dimensions of $5.3 \times 6.2 \mathrm{~cm}$ (Figure 1).

Complete surgical removal of the tumour was achieved through a minithoracotomy (Figure 2). Histological analysis confirmed the diagnosis of myxoid neurofibroma (Figure 3).

Given this histological diagnosis, the patient was re-examined and many café au lait spots (more than 6, larger than $15 \mathrm{~mm}$ in diameter) and neurofibromas (elastic tissue) were observed (Figure 4). Further tests were carried out to rule out other conditions related to NF1 but produced no relevant findings, and the patient was diagnosed with NF type 1 (von Recklinghausen's disease).

\section{Discussion}

Neurofibromatosis has three main forms: i) NF type 1; ii) NF type 2; and iii) Schwanno-

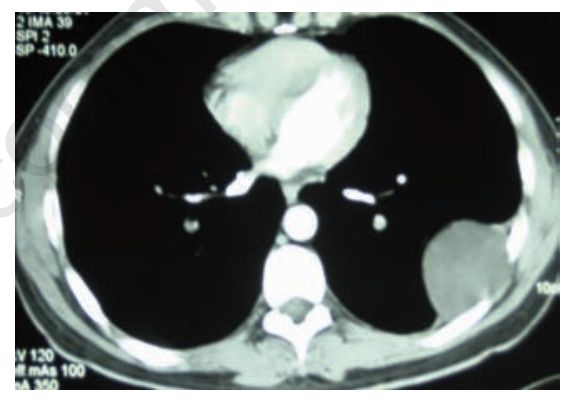

Figure 1. Computed tomography image of the mass.

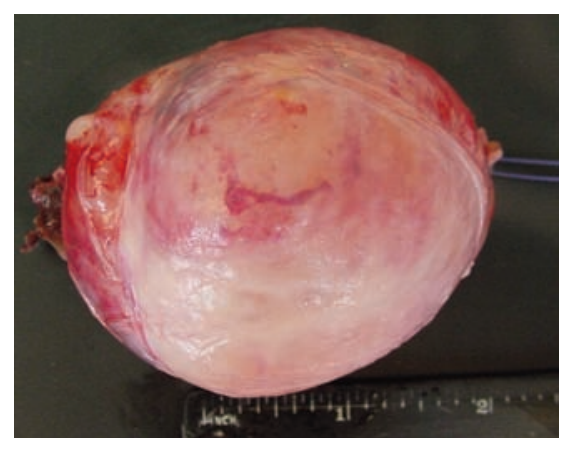

Figure 2. Macroscopical view of the surgical piece.
Correspondence: Borja Aguinagalde. Paseo Mons 76.1A. 20015 San Sebastian-Donostia.

Tel. +34.627439590 - Fax: +34 943860647.

E-mail: aguinavali@hotmail.com

Key words: neurofibromatosis, thoracic wall, pathology.

Contributions: BA, manuscript drafting and reviewing, searching process, diagnosis performing; JZ, manuscript drafting and searching process; MF, manuscript reviewing; NB, searching process; CL, pathology help; JMI, manuscript reviewing.

Conflict of interests: the authors declare no potential conflict of interests.

Received for publication: 2 September 2011.

Revision received: 29 April 2012.

Accepted for publication: 2 May 2012.

This work is licensed under a Creative Commons Attribution NonCommercial 3.0 License (CC BYNC 3.0).

CCopyright B. Aguinagalde et al., 2012

Licensee PAGEPress, Italy

Clinics and Practice 2012; 2:e10

doi:10.4081/cp.2012.e10

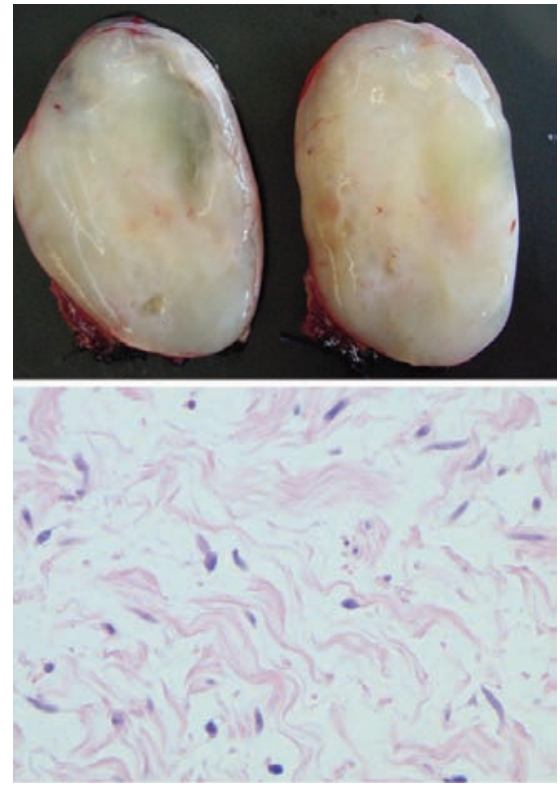

Figure 3. Histological image of the mass.

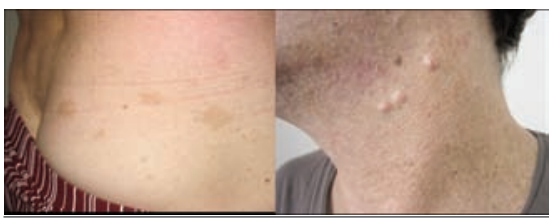

Figure 4. Café au lait spots and cutaneous neurofibromas. 
Table 1. Seven diagnostic criteria for neurofibromatosis.

NF1 - two or more of the following criteria

Six or more café au lait macules larger than $5 \mathrm{~mm}$ in diameter in prepubertal children or $15 \mathrm{~mm}$ in diameter in postpubertal individuals.

Two or more neurofibromas of any form or one plexiform neurofibroma.

Crowe's sign (freckling in the axillary or inguinal regions)

Optic glioma

Two or more Lisch nodules (iris hamartomas)

A distinctive osseous lesion (such as, sphenoid dysplasia or thinning of long bone cortex, with or without pseudoarthrosis)

A first-degree relative (parent, sibling, or offspring) diagnosed with NF1

NF1, neurofibromatosis type 1.

matosis. These are a group of genetic disorders associated with a predisposition to nerve tumours. NF type 1 is the most common form with a prevalence of 1 in 3000 people. It has an autosomal dominant pattern of inheritance with complete penetrance but variable expression though many cases are believed to arise due to spontaneous mutations. To diagnose the disorder, it is considered necessary for patients to meet at least two of the seven diagnostic criteria (Table 1).

Neurofibromas are the most characteristic type of tumour in this disorder. These are benign tumours composed of Schwann cells, fibroblasts, mast cells and pericytes. ${ }^{2}$ In addition, café au lait macules are also very common. Although neurogenic tumours that cause neuropathic pain have been described, our patient had an intercostal tumour with no associated symptoms and this was found to be a neurofibroma. ${ }^{3}$ After surgery, it was observed that he had many café au lait spots (larger than $15 \mathrm{~mm}$ in diameter) as well as cutaneous neurofibromas, so a definitive diagnosis of $\mathrm{NF}$ type 1 was made.

In the literature, we have only found reports of eight cases of neurogenic tumours originating from an intercostal nerve; only two of these corresponded to neurofibromas (the others were neurilemmomas). Among these two patients,,${ }^{4,5}$ only one was a case of NF type 14 and, in contrast to our case, the diagnosis was reached prior to surgery. Treatment is based on complete removal of the tumour, even in cases with no symptoms, as neurofibromas may become malignant. Surgery can be performed thoracoscopically or through a minithoracotomy. To conclude, we present a very rare case of intercostal nerve neurofibroma leading to a definitive diagnosis of type 1 neurofibromatosis.

\section{References}

1. Strollo DC, Rosado-de-Christenson ML, Jett JR. Primary mediastinal tumors: II. Tumors of the middle and posterior mediastinum. Chest 1997;112:1344-57.

2. Lu-Emerson C, Plotkin S.R. The neurofibromatoses. Part 1: NF1. Rev Neurol Dis 2009;6:E47-E53.

3. GM Jeppesen. Intercostal neurinoma as a cause of recurrent chest pain. Ugeskr Laeger 1996;158:5310-1.

4. Salazar F, Machado A, Murthy S, Boulis NM. Thoracoscopically guided transaxillary resection of adjoining intercostal plexiform neurofibromas: review of mosaicism in neurofibromatosis: technical note. Neurosurgery 2005;57:0NS-407.

5. Park SJ, Kim HJ, Lee HB, et al. Solitary neurofibroma of intercostal region in a patient without neurofibromatosis type 1 . Am J Med Sci 2008;336:278. 